\title{
Detection of Salmonella Enterica in Egg Yolk by PCR on a Microfluidic Disc Device Using Immunomagnetic Beads
}

\author{
Izumi Kubo ${ }^{1, *}$, Mitsutoshi Kajiya ${ }^{1}$, Narumi Aramaki ${ }^{1}$ and Shunsuke Furutani ${ }^{2,3}$ \\ 1 Graduate School of Engineering, Soka University, 1-236 Tangi, Hachioji, Tokyo 192-8577, Japan; \\ pride-gose-before-destruction@docomo.ne.jp (M.K); tmi_25v17_sle@docomo.ne.jp (N.A.) \\ 2 Biomedical Research Institute, National Institute of Advanced Industrial Science and Technology (AIST), \\ 1-8-31 Midorigaoka, Ikeda, Osaka 563-8577, Japan; shunsuke-furutani@aist.go.jp \\ 3 Advanced Photonics and Biosensing Open Innovation Laboratory, National Institute of Advanced Industrial \\ Science and Technology (AIST), 2-1 Yamadaoka, Suita, Osaka 565-0871, Japan \\ * Correspondence: kubo@soka.ac.jp; Tel.: +81-42-691-9450
}

Received: 30 December 2019; Accepted: 11 February 2020; Published: 15 February 2020

\begin{abstract}
Salmonella enterica is a pathogenic bacterium that causes foodborne illness. One of the vehicle foods of $S$. enterica are chicken eggs. Efficient collection of the bacterium is necessary to detect it specifically. We developed a method to detect $S$. enterica by PCR on a microfluidic disc device using a fluorescent probe. Salmonella enterica cells were isolated in the microchambers on the device, followed by thermal lysis and PCR targeting with the invA gene, a gene specific to $S$. enterica, were observed by measurement of the fluorescent signal that resulted from gene amplification. However, the developed method was unable to discriminate viable cells from dead cells. Consequently, in this study, magnetic beads modified with anti-Salmonella antibody were utilized to detect viable Salmonella cells from egg yolk prior to PCR on the device. While using the antibody-modified beads, egg yolk components, which inhibit PCR, were removed. The collected cells were subsequently detected by PCR of the invA gene on a microfluidic disc device. This method enabled the detection of viable cells without the inhibition of PCR by any egg component. S. enterica was detected at $5.0 \times 10^{4}$ cells $\mathrm{mL}^{-1}$ or at a higher concentration of egg yolk within $6 \mathrm{~h}$ including the sampling time.
\end{abstract}

Keywords: immunomagnetic beads; Salmonella enterica; PCR; invA; egg yolk

\section{Introduction}

Salmonella enterica is a dangerous pathogen that causes outbreaks of foodborne illness [1]. The vehicle foods of S. enterica are eggs, meat, and foods made of eggs or meat [2-5]. Cells of S. enterica exist in the intestines of chickens as a coliform bacterium, allowing the easy contamination of chicken meat and eggs [6,7]. Infection of S. enterica can occur not only from contaminated eggs or meat but also from its contamination through food processing, transportation, packaging, sales, cooking, and serving. When contaminated food is consumed, after an incubation period of 6 to $48 \mathrm{~h}$, symptoms such as vomiting, diarrhea, and/or fever appear [8,9].

In order to prevent outbreaks, rapid detection of the origin of this bacterium in food is necessary. A conventional method to determine the origin of a bacterium requires multiple culture steps. Coupled with limited dilution analysis, a conventional culture-based method is highly sensitive, and few colony forming units per $\mathrm{mL}(\mathrm{CFU} / \mathrm{mL})$ can be detected. However, it takes as long as 5 to 6 days to know whether food is contaminated by S. enterica [10].

On the other hand, the polymerase chain reaction (PCR) has recently been used for the rapid detection of pathogenic bacteria. The PCR can amplify specific genes of S. enterica to millions of 
copies within $2 \mathrm{~h}$ [11]. There are two major methods to detect a PCR amplicon. Electrophoresis is a conventional and inexpensive method, but after PCR, it takes one hour to separate and detect the PCR amplicon [12]. A method that does not need electrophoresis after PCR, such as real-time PCR, would enable rapid detection of a gene. Real-time PCR is based on the binding of a fluorescent probe to the amplicon allowing fluorescent measurement to provide information about the increase of the amplicon. However, reagents used for real-time PCR are expensive, so a reduction in the amount of reagents used is desirable to inspect many samples [13,14].

We developed an original microfluidic device with a compact disc-liked shape for cell isolation [15]. This device has 24 microchannels that spin from the center to the periphery, and each microchannel has 300 or more microchambers. The volume of each microchamber is approximately $1 \mathrm{~nL}$ [16]. Detection of bacterial cells on the device was proposed and performed based on PCR on the device.

In this system, at first, bacterial cells are suspended in PCR reagent which is used to detect the specific gene of the target bacterial cells. When $1 \mu \mathrm{L}$ of a liquid suspension of the microbial cells including the target bacterial cells is introduced into an inlet of a microchannel, centrifugal force can isolate these cells in each microchamber during rotation of the device [15]. After cells are entrapped in the microchambers, cells are lysed in the chambers by heat treatment at $95^{\circ} \mathrm{C}$. Without taking out cells or genes from the cells after lysis, PCR of a specific gene of the entrapped cells can be performed on the device. This process is referred to as hot cell-direct PCR [17]. Using a fluorescent probe for the PCR product, a PCR amplicon can be detected under an epifluorescent microscope [18]. Throughout the process, an entrapped cell can be detected with the use of this device. Use of a fluorescent probe enables a reduction in analysis time compared with the electrophoretic detection method. Moreover, microfluidic detection reduces the consumption of PCR reagents which are used in real-time PCR detection.

In our previous study, we developed a method to detect S. enterica by PCR on this microfluidic disc device. S. enterica cells were isolated in the microchambers on the device, followed by thermal lysis and PCR targeting of the invA gene, which is a specific gene of S. enterica [19]. It was confirmed that $S$. enterica at a concentration of 50,000 cells/mL could be detected with the PCR reagents, smaller than one-tenth of Real-time PCR.

Furthermore, we detected S. enterica in chicken meat using this device. First, S. enterica was separated from chicken meat in a stomacher bag (Atect, Osaka, Japan) and collected by centrifugation using Percoll ${ }^{\circledR}$. Salmonella enterica cells collected at 460,000 CFU/g could be detected within $4 \mathrm{~h}$ including sampling and detection [11]. Although the invA gene from S. enterica could be detected efficiently using this procedure, the gene from viable cells might not be distinguished from the gene in dead cells. Viable $S$. enterica cells are known to cause critical illness, but dead cells do not cause illness [20]. Detection of viable pathogenic cells is necessary to prevent an outbreak. For this reason, Ohtsuka and coworkers [5] performed an enrichment culture for $20 \mathrm{~h}$ before amplification of the S. enterica gene to detect viable cells.

Eggs are another main vehicle of S. enterica. The bacterium contaminates raw eggs that are used widely to produce mayonnaise and salad dressing. Since raw eggs form a very thick liquid that contains proteins and lipid, it is not easy to collect bacterial cells from raw eggs. During sample preparation, Salmonella cells are collected by filtration, centrifugation, and the use of immunomagnetic beads on which an anti-Salmonella antibody is modified.

The aim of this study was to establish a method to collect viable bacteria removing the egg yolk components from S. enterica in an egg sample and to apply hot cell-direct PCR on the microfluidic disc device to detect the invA gene. The established method can offer a rapid and economic formula to detect viable $S$. enterica in eggs. 


\section{Materials and Methods}

\subsection{Bacterial Cells and Medium}

S. enterica was purchased from RIKEN BRC (Tsukuba, Japan). Nutrient broth (Sanko Junyaku Co., Ltd., Tokyo, Japan) with $0.5 \% \mathrm{NaCl}$ medium (NB medium) (pH 7.2) was used as the culture medium for S. enterica cells. S. enterica cells were cultured overnight in the liquid media at $37^{\circ} \mathrm{C}$. Cell concentration was confirmed under an optical microscope (BH-2, Olympus, Tokyo, Japan) and diluted to the desired concentration with $10 \mathrm{mM}$ phosphate buffer saline solution (PBS). To obtain dead cells, the cultured cells were autoclaved at $120^{\circ} \mathrm{C}$ for $20 \mathrm{~min}$. Buffered peptone water (BPW) (pH 7.2) was used to dilute egg yolk.

\subsection{Collection of Cells Using Percoll ${ }^{\circledR}$}

Bacterial samples from egg yolk as the food sample were prepared as follows. Sterile egg yolk was obtained from Atect (Osaka, Japan) as the food sample. Five mL of egg yolk and $45 \mathrm{~mL}$ of BPW were mixed to form an egg yolk solution and one $\mathrm{mL}$ of $S$. enterica suspension was spiked to the egg yolk solution. S. enterica cells were collected from a cell suspension in egg yolk solution by centrifugation, performed as follows. Egg yolk solution $(1 \mathrm{~mL})$ was spiked by the cells to $5 \times 10^{7}$ cells $/ \mathrm{mL}$ and mixed with $0.7 \mathrm{~mL}$ of Percoll ${ }^{\circledR}$ (GE Healthcare Japan Corp., Tokyo, Japan) which is a low viscosity gradient medium for bacterial cell preparation [21]. After the mixture was centrifuged at 14,000 rpm for $15 \mathrm{~min}$ at $4{ }^{\circ} \mathrm{C}, 0.5 \mathrm{~mL}$ of precipitate was collected as the $S$. enterica sample. After washing the sample with $10 \mathrm{mM}$ PBS three times, $5 \mu \mathrm{L}$ of the obtained precipitate was mixed with $20 \mu \mathrm{L}$ of PCR reagent and used for hot cell-direct PCR.

\subsection{Filtering S. Enterica from Egg Yolk}

Polycarbonate membrane filters (ISOPORE ${ }^{\mathrm{TM}}$ membrane filters, MerckMillipore, Tokyo, Japan) with a pore size of 3.0, 0.8, and $0.4 \mu \mathrm{m}$ was examined for the filtration of $S$. enterica cells. Five microliters of sample spiked by $S$. enterica cells $\left(5.0 \times 10^{5} \mathrm{CFU} / \mathrm{mL}\right)$ were directly applied to a filter and filtered cells were counted under an optical microscope.

\subsection{Collection of S. Enterica from Egg Yolk Using Immunomagnetic Beads}

To collect S. enterica cells from egg yolk, the use of immunomagnetic beads was investigated. The method to collect viable $S$. enterica cells from egg yolk using immunomagnetic beads (Dynabeads ${ }^{\circledR}$ anti-Salmonella, Applied Biosystems by Life Technologies, Tokyo, Japan) is described next (Figure 1). The $S$. enterica cells were spiked to a sterile egg yolk, and one volume of the egg yolk sample was mixed with four volumes of BPW to lower the viscosity of the sample according to a suggested method [22]. The spiked concentration added to one $\mathrm{mL}$ of egg yolk was $5 \times 10^{3}-5 \times 10^{7}$ cells $/ \mathrm{mL}$. In a solution with low viscosity, bacterial cells are expected to bind efficiently to the antibody on the beads. At first, $1 \mathrm{~mL}$ of the sample solution and $10 \mu \mathrm{L}$ of the bead suspension $\left(5 \times 10^{8}\right.$ beads $\left./ \mathrm{mL}\right)$ were mixed in a micro tube (1.5 mL, CF-0150, INA-OPTICA, Osaka, Japan). In preliminary experiments, the volume of the bead suspension was examined in $10-40 \mu \mathrm{L}$, and $10 \mu \mathrm{L}$ of the suspension was enough to bind $10^{8}$ cells. The sample solution and beads suspension were incubated for $20 \mathrm{~min}$ at room temperature to allow bacterial cells to bind to the antibody on the beads. Thereafter, beads were collected by placing the tube in a magnetic plate (DynaMag- $2^{\circledR}$, Applied Biosystems by Life Technologies) for 3 min and washed four times with PBST (0.15 M NaCl, 0.01 M phosphate buffer, 0.05\% Tween-20, pH 7.4).

Washing removes the egg yolk completely, and S. enterica cells are trapped on the immunomagnetic beads which can then be collected. Finally, all the collected beads were suspended in $100 \mu \mathrm{L}$ of PBST. 


\section{egg yolk sample spiked with S.enterica}

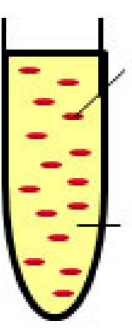

S.enterica

suspention ( $1 \mathrm{~mL}$ )

sterile egg yolk $(5 \mathrm{~mL})$

(5 fold diluted with

buffered peptone water)

immunomagnetic

beads $(10 \mu \mathrm{L})$

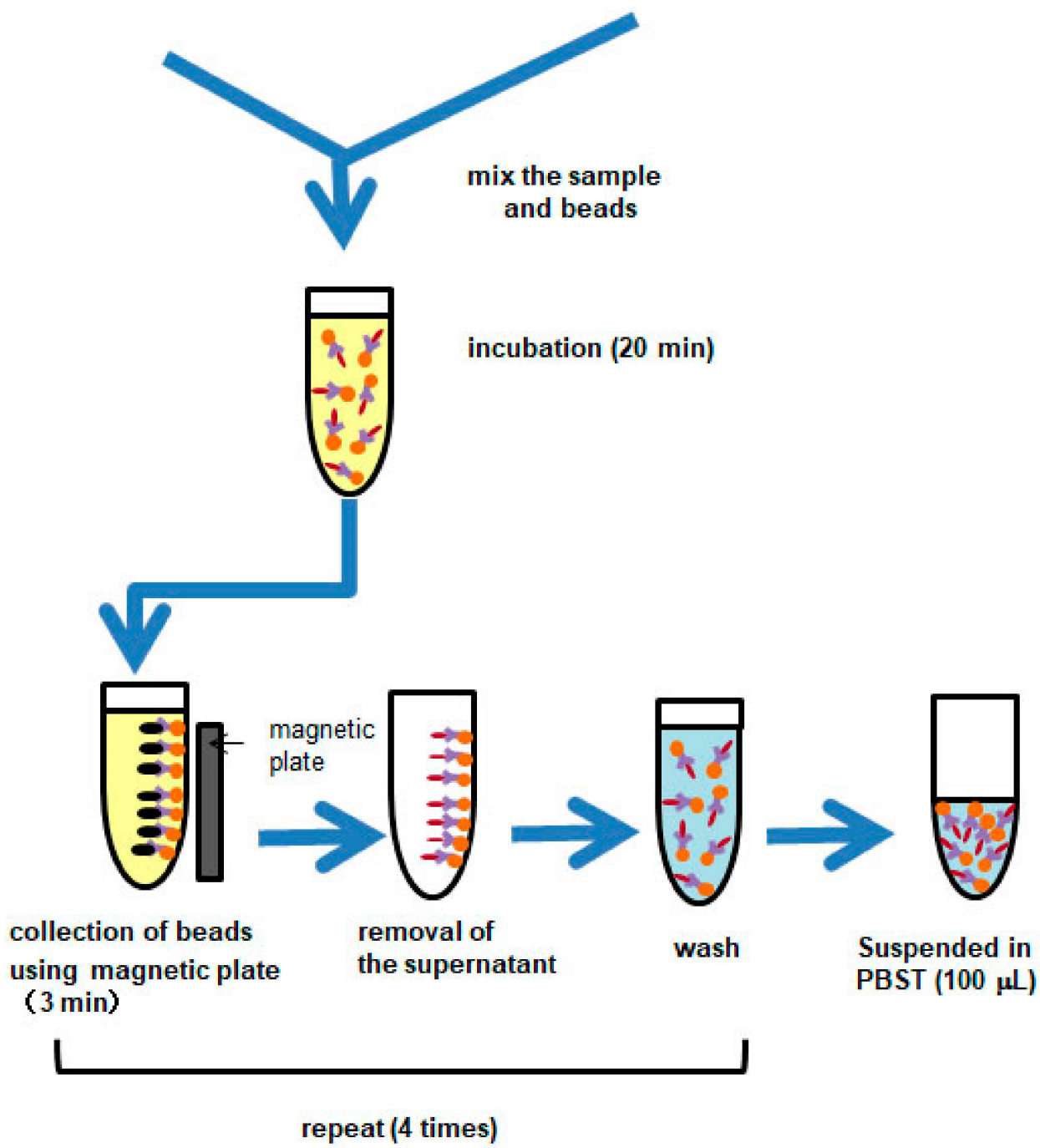

Figure 1. Sample preparation procedure from egg yolk sample spiked with Salmonella enterica using immunomagnetic beads: PBST (0.15 M NaCl, 0.01 M phosphate buffer, $0.05 \%$ Tween-20, $\mathrm{pH} 7.4$ )

\subsection{Colony Formation after Collection of Immunomagnetic Beads}

To examine the collection of viable cells by beads, colony formation was performed as follows. One milliliter of the suspension of S. enterica in egg yolk was mixed with $10 \mu \mathrm{L}$ of beads suspension $\left(5 \times 10^{6}\right.$ beads $)$ in a microtube and incubated for $20 \mathrm{~min}$ at room temperature as shown in Figure 1 . Then, the beads were collected by placing the tube in a magnetic plate as explained in Section 2.4. It was washed with PBST three times and suspended in $1 \mathrm{~mL}$ of PBST. After 1000 fold dilution by PBST, $100 \mu \mathrm{L}$ of the suspension was used for colony formation. As a control experiment, the same 
suspension of $S$. enterica served for colony formation after the same dilution. The number of colonies was confirmed by culture on NB agar medium at $37^{\circ} \mathrm{C}$ for $24 \mathrm{~h}$.

\subsection{PCR Reagents and Detection of PCR Product in a Microtube}

The PCR reagent used was a Cycleave PCR Salmonella detection Kit Ver. 2.0 (TaKaRa, Tokyo, Japan) which is designed to detect the invA gene of $S$. enterica. This kit contains not only all the reagents to detect the invA gene using a fluorescent probe labeled with 6-carboxyfluorescein (FAM) but also an internal control DNA sequence, primers, and a probe labeled with X-Rhodamine (ROX) to confirm PCR performance. The internal control DNA works by investigating whether there are interference compounds in the sample or not. When the internal control DNA shows a positive signal after PCR, this indicates the absence of PCR inhibition while in the same sample, a signal of the target gene is not increased, indicating that the concentration of the target gene in the sample is below the detection limit. When both target and internal control are not detected, this indicates that PCR did not occur properly and that a reaction inhibitory factor exists in the sample [11]. The reaction mixture without $S$. enterica was used as the negative control.

In the PCR in a micro tube, cultured S. enterica recovered by Percoll ${ }^{\circledR}$ was used as a template for PCR of the invA gene. The PCR was performed with a 7500 Real-Time PCR System (Applied Biosystems, Tokyo, Japan). Thermal cycling was initiated at $95^{\circ} \mathrm{C}$ for 2 min to lyse S. enterica, followed by 40 cycles of $95^{\circ} \mathrm{C}$ for $5 \mathrm{~s}, 55^{\circ} \mathrm{C}$ for $10 \mathrm{~s}$, and $72{ }^{\circ} \mathrm{C}$ for $30 \mathrm{~s}$ according to a previously reported method [11].

\subsection{Microfluidic Disc Device}

The microfluidic disc device was designed to isolate small particles such as cells and micro beads [15]. The microchannel and microchambers were fabricated on a silicon wafer by deep reactive ion etching based on photolithography according to a previously reported method [19]. The prepared silicon wafer with microchannels and microchambers was bonded to a glass plate with holes for inlets and vents [19]. As shown in Figure 2a, on the microfluidic disc device, zig-zag-shaped microchannels were arranged, and 313 microchambers were arrayed on each microchannel (Figure 2b). The sizes of microchannels and microchambers are shown in Figure $2 \mathrm{~d}$. The surface of the microchannels and microchambers was modified by triethoxymethylsilane (Wako, Osaka, Japan) to prevent the migration of the liquid after it was trapped in microchambers [11].

\subsection{Detection of S. Enterica on the Microfluidic Disc}

Detection of $S$. enterica on the microfluidic disc was performed as follows. The collected cell suspension $(2 \mu \mathrm{L})$ was mixed with PCR reagent $(8 \mu \mathrm{L})$. A mixture of cell suspension $(1 \mu \mathrm{L})$ was applied to the inlet of the microfluidic disc and the disc was rotated for $30 \mathrm{sec}$ at $3000 \mathrm{rpm}$ to entrap cells in microchambers (Figure 2 C). Lysis of cells, and PCR was performed by a previously reported procedure [11]. In brief, thermal lysis was performed for $2 \mathrm{~min}$ at $95{ }^{\circ} \mathrm{C}$ after the entrapment of cells in microchambers and PCR $\left(40\right.$ cycles $95{ }^{\circ} \mathrm{C}$ for $5 \mathrm{~s}, 55^{\circ} \mathrm{C}$ for $10 \mathrm{~s}$, and $72{ }^{\circ} \mathrm{C}$ for $\left.10 \mathrm{~s}\right)$ was conducted on the disc. Before and after PCR, the disc was fixed on the automatically controllable stage and fluorescent intensity of microchambers was observed and acquired through an epifluorescent microscope (Olympus, Tokyo, Japan) equipped with a CCD camera (Clara, Andor, Northern Island, UK).

Images of microchambers were obtained except for those near the inlet and vent because of limitations in the movable area of the stage. From the obtained fluorescent image, the fluorescent intensity of each microchamber was measured. The relative fluorescence intensity (RFI) is expressed as:

$$
\mathrm{RFI}=\frac{\text { Fluorescence intensity after PCR }}{\text { Fluorescence intensity before PCR }}
$$


where RFI indicates the existence of a PCR product.

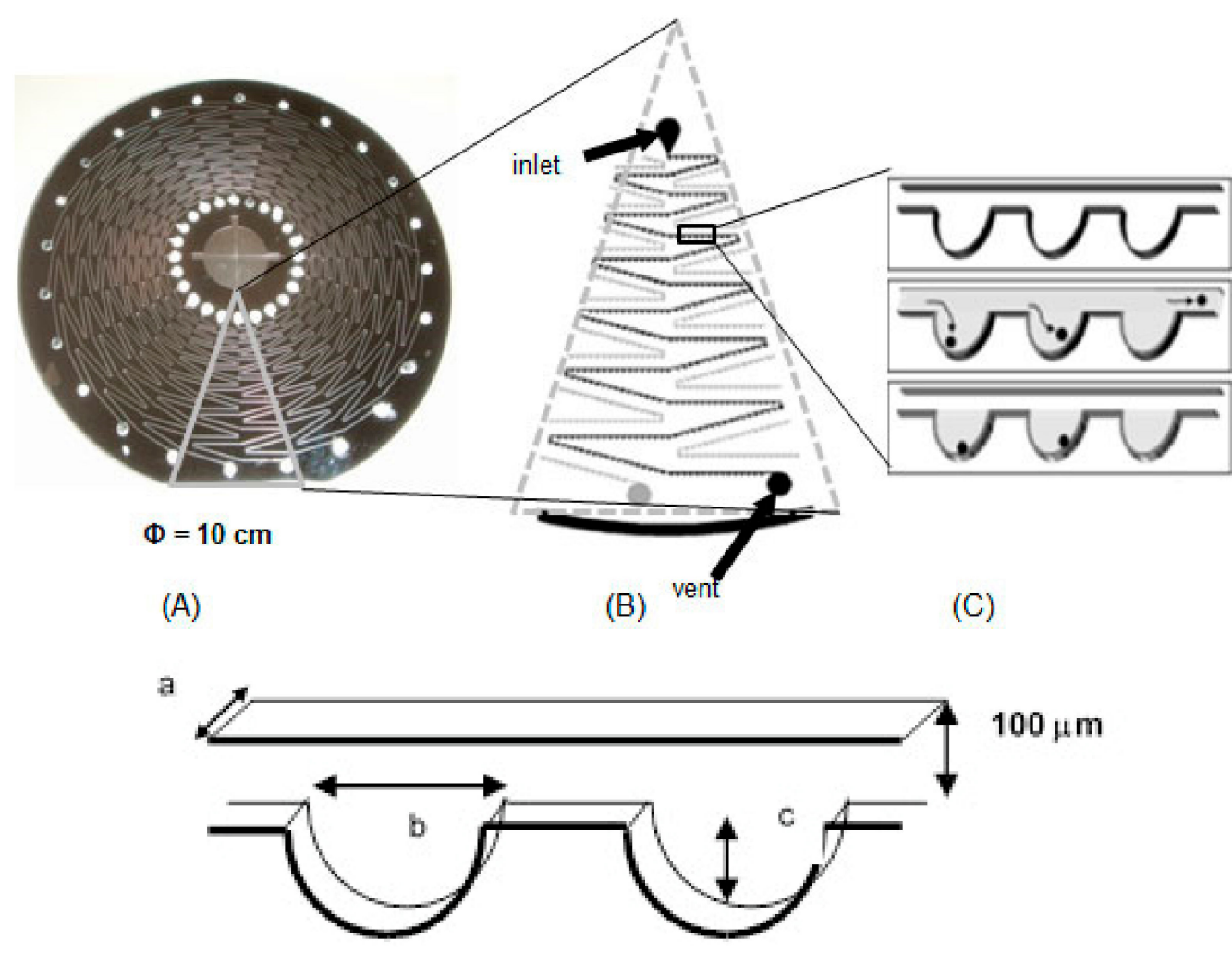

(D)

Figure 2. The microfluidic disc device: (A) micro fluidic disc device; (B) microchannel on the microfluidic disc device; (C) microchambers and entrapment of cells. (1) Microchambers are arrayed along the microchannel; (2) cell suspension flows through the microchannel; (3) cells are trapped in microchambers by centrifugal force (3000 rpm, $30 \mathrm{~s}$ ), (D) size of microchannel and microchambers: (a) $40 \mu \mathrm{m}$, (b) $300 \mu \mathrm{m}$, (c) $200 \mu \mathrm{m}$.

\section{Results}

\subsection{Effect of Egg Yolk on PCR}

In our previous study, S. enterica cells were separated from chicken meat with the use of a stomacher bag with filter which is useful for separating small bacterial cells from solid samples, such as meat, collected by centrifugation using Percoll ${ }^{\circledR}[11]$. The egg sample was a liquid, not a solid. It was considered that the stomacher bag was not effective to separate bacterial cells from an egg sample, so centrifugation using Percoll ${ }^{\circledR}$ was examined in this study to collect $S$. enterica cells. We investigated first whether the collection of $S$. enterica cells using Percoll ${ }^{\circledR}$ could effectively remove egg yolk components or not. To assess the effectiveness, the collected samples in the tubes were examined by PCR as described in Section 2.6.

Without egg yolk, precipitate from S. enterica suspension in BPW after centrifugation showed an increase in FAM PCR signals from the inv $A$ gene to a 2.5 fold higher rate of fluorescence relative to before PCR while ROX PCR signals from the internal control gene also increased by 10.4 fold (Figure 3). These ratios of fluorescence after PCR were almost the same as those after collection of S. enterica cells from meat samples [11]. This means that without egg yolk, PCR was performed without inhibition. However, the precipitate from the egg yolk sample with and without $S$. enterica cells showed little increase of both FAM (invA) and ROX (internal control) PCR signals. This implies that 
egg yolk components inhibit PCR. This result indicates that the egg yolk component(s) remaining in the precipitate after the centrifugation using Percoll ${ }^{\circledR}$ inhibited PCR. The sample, when diluted 10 times by BPW, showed a small increase in PCR signals, whereas a 160 fold dilution of BPW showed almost the same increase in PCR signals as when no egg yolk was present. A 10 fold dilution was not enough to avoid inhibition of PCR by egg yolk components. Although a 160 fold dilution was enough to avoid the inhibition, the concentration of S. enterica would be lower than the detection limit following this dilution.

To perform PCR without inhibition, it was clear that in the process of collection of S. enterica cells, the egg yolk component should be completely removed, but centrifugation using Percoll ${ }^{\circledR}$ was not an effective strategy to remove the egg yolk component.

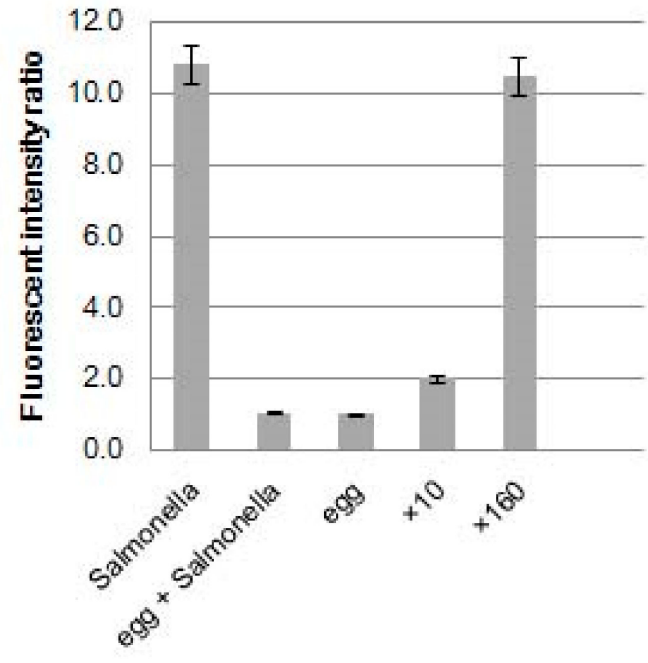

(a)

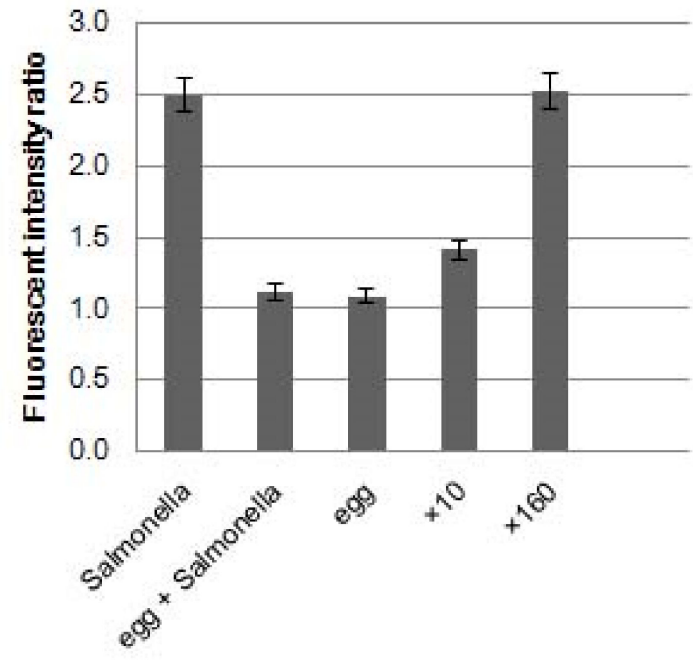

(b)

Figure 3. Effect of egg yolk components on fluorescence intensity via PCR: (a) PCR signal of 6-carboxyfluorescein (FAM) from the invA gene; (b) PCR signal of X-Rhodamine (ROX) from the internal control, $N=3$.

\subsection{Filtration of Egg Yolk}

An attempt was made to separate bacterial cells from the egg yolk component by filtration with the use of a polycarbonate membrane filter with pores that were smaller than bacterial cells with sizes of approximately $1 \mu \mathrm{m}$ according to our observations under an optical microscope. It was examined whether there was an appropriate pore size to trap $S$. enterica cells and remove egg yolk components. The filter was that was most appropriate to trap bacterial cells was initially examined. As shown in Table 1, a filter with a pore size of 3.0 and $0.8 \mu \mathrm{m}$ could not trap cells completely, while a filter with a pore size of $0.5 \mu \mathrm{m}$ trapped $91 \%$ of cells (Table 1). Then, the sample suspended in egg yolk solution was applied to the filters. Although the suspension passed through filters with a pore size 3.0 and $0.8 \mu \mathrm{m}$, it could not pass through the filter with a pore size of $0.5 \mu \mathrm{m}$. Thus, S. enterica cells in the egg yolk sample could not be separated from the egg yolk using membrane filters.

Table 1. Filtration of Salmonella enterica in egg yolk solution through polycarbonate membranes.

\begin{tabular}{cccc}
\hline Filter & $\underline{\mathrm{A}}$ & $\underline{\mathrm{B}}$ & $\underline{\mathrm{C}}$ \\
\hline Pore size, $\mu \mathrm{m}$ & 3.0 & 0.8 & 0.4 \\
\hline Recovery of Cells, $\%$ & 0 & 7 & 91 \\
\hline Passage of Egg Yolk Solution & $\bigcirc$ & $\bigcirc$ & $\times$ \\
\hline
\end{tabular}




\subsection{Detection of S. Enterica after Removal of Egg Yolk Using Immunomagnetic Beads}

Since the use of polycarbonate membranes was ineffective, the collection of $S$. enterica cells from the egg yolk sample was investigated using immunomagnetic beads ( $\varphi=2 \mu \mathrm{m}$, Supplementary 1). Dynabeads ${ }^{\circledR}$ anti-Salmonella react with all current Salmonella serovars, and the protocol using these beads serves to determine the presence of viable Salmonella [23]. To examine whether the beads collect viable cells, collected cells were counted by colony formation. At the same concentration $\left(5 \times 10^{5}\right.$ cells $\left./ \mathrm{mL}\right)$, the sample after beads collection showed that $4.8 \pm 0.2 \times 10^{5}$ cells $/ \mathrm{mL}$ were obtained. This indicates that $96 \% \pm 4 \%$ of viable cells were collected using the immunomagnetic beads.

In order to examine whether $S$. enterica collected from egg yolk using these beads could be detected by PCR or not, we performed PCR in a tube. The fluorescence intensity ratio after the 40th cycle relative to the first cycle was also evaluated (Figure 4).

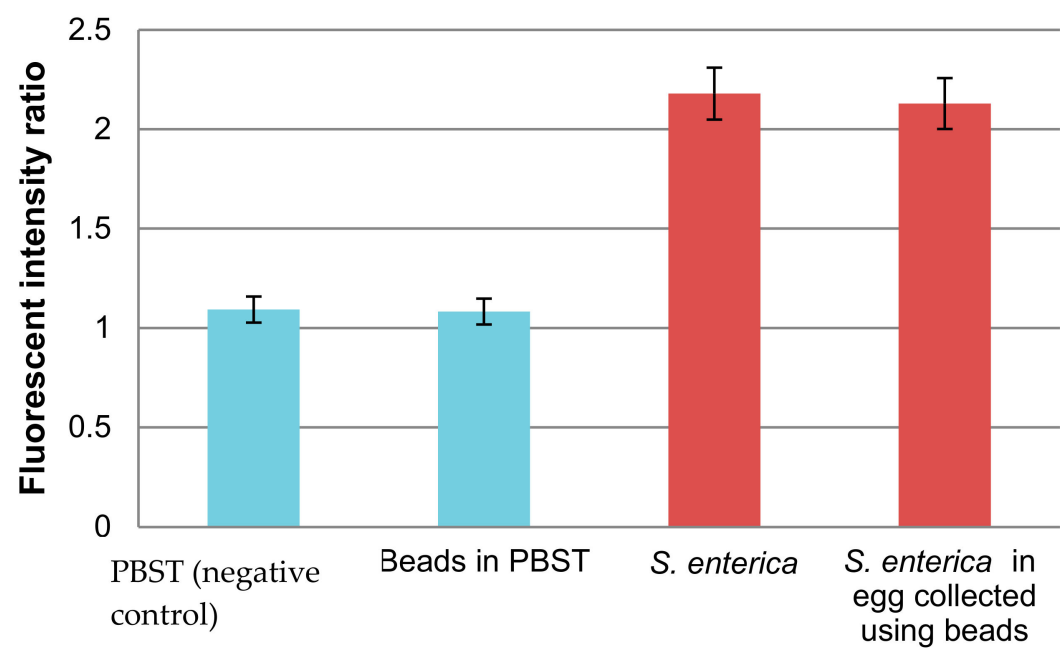

Figure 4. Effect of immunomagnetic beads on the PCR of $i n v A$ in a tube. Concentration of $S$. enterica = $5 \times 10^{5}$ cells $/ \mathrm{mL}, N=3$.

The fluorescence intensity ratio of S. enterica cells collected from egg yolk with beads was about two-fold higher than the negative control and almost the same value as S. enterica at the same concentration. Therefore, by using immunomagnetic beads, egg yolk components could be removed completely, and PCR was not inhibited. The egg yolk component was sufficiently removed so that S. enterica cells could be collected by microbeads, and the inv $A$ gene in cells could be detected by PCR. Autoclaved S. enterica cells as well as viable cells were examined. The collected beads did not show an increase in fluorescent intensity after PCR. Only viable cells were detected after collection by immunomagnetic beads.

\subsection{Detection of S. Enterica by PCR on The Microfluidic Disc}

Salmonella enterica cells were successfully collected from egg yolk with the use of the immunomagnetic beads. The S. enterica collected from egg yolk using these beads served for the detection of the inv $A$ gene by PCR on the microfluidic disc. The obtained suspension of beads after binding to bacterial cells and removal of egg yolk was mixed with the PCR reagent. The mixture $(1 \mu \mathrm{L})$ was injected into the inlet of the microchannel on the disc.

Figure 5 shows the after-to-before ratio of fluorescent intensity (RFI) by PCR of each microchamber on the microchannel. Microchambers were numbered from upstream (inlet) to downstream (outlet); this figure shows the RFI of each chamber from upstream to downstream. In our previous study, RFI of the negative control was lower than the threshold value 1.4 [11]. A chamber with higher RFI than the threshold was determined to be a chamber that trapped S. enterica cells. When the concentration 
of $S$. enterica was $5 \times 10^{5}$ cells $/ \mathrm{mL}$, chambers with an RFI value that exceeded the threshold could be confirmed.

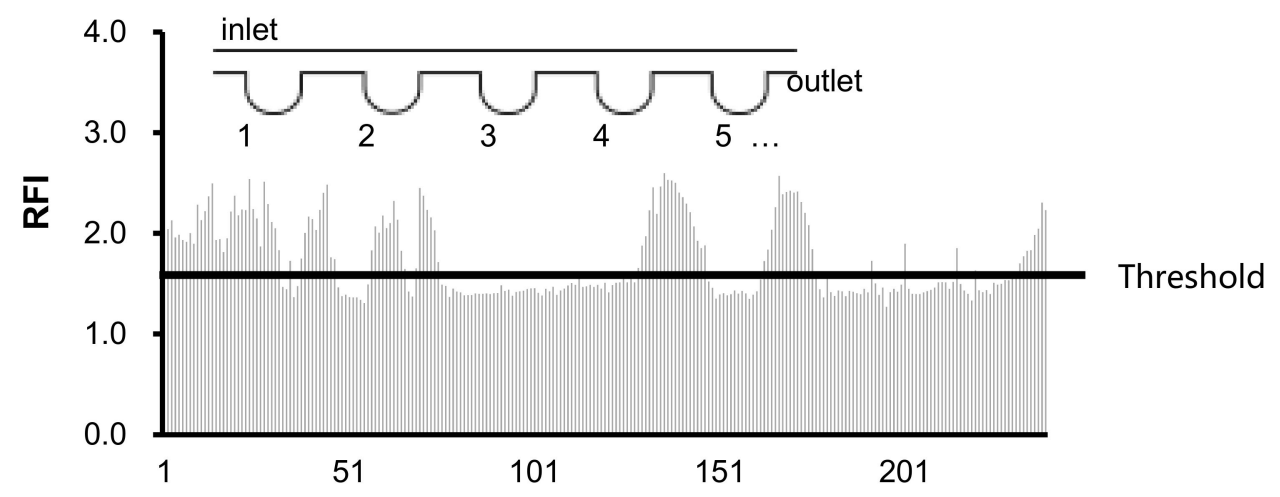

\section{Chamber number}

Figure 5. Detection of S. enterica by PCR on the microfluidic disc.

The concentration dependence of the increase in fluorescence was examined next. Figure 6 shows the average value of the intensity ratio of observed chambers of each concentration of $S$. enterica from the range of $5 \times 10^{3}$ sssscells $/ \mathrm{mL}$ to $5 \times 10^{7}$ cells $/ \mathrm{mL}$ which are the spiked concentrations into $1 \mathrm{~mL}$ of egg yolk. The averaged value of RFI increased depending on the concentration of S. enterica. The regression line was $\mathrm{y}=0.176 \ln (\mathrm{x})-0.483$ and $R^{2}=0.96$.

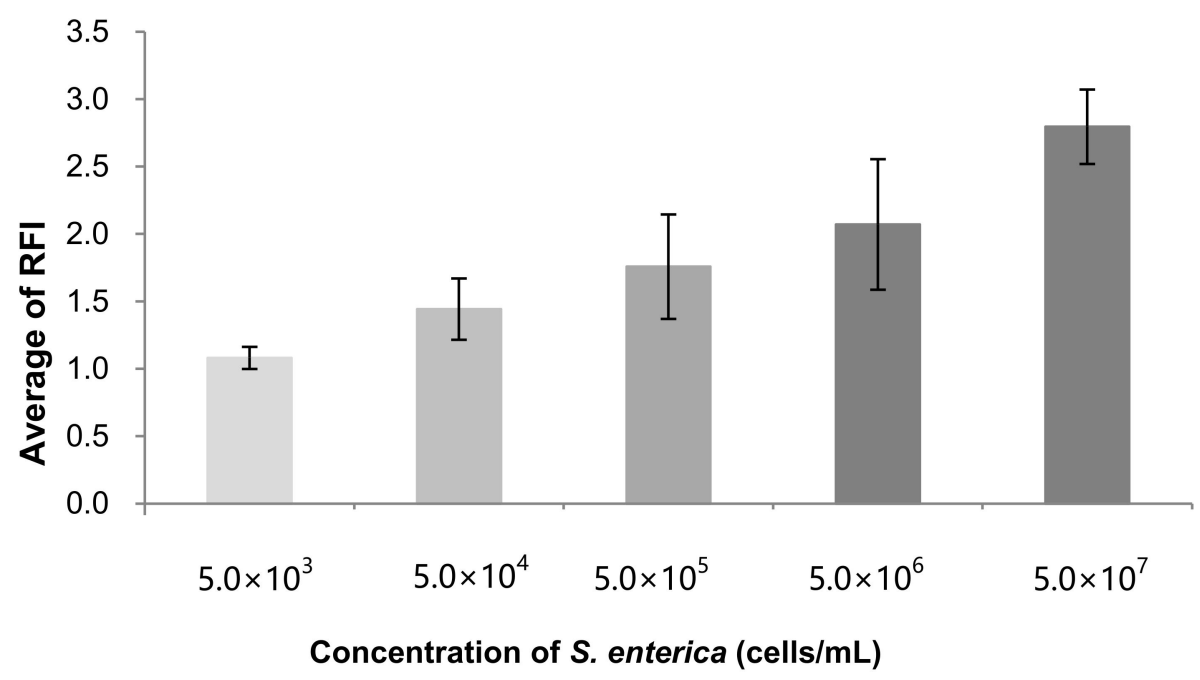

Figure 6. Concentration dependence of S. enterica cells on average RFI.

3.5. Dependence of the Number of Microchambers that Exceeded the Threshold on the Concentration of S. enterica Cells

Figure 7 shows the number of chambers that exceeded the threshold RFI of each concentration of S. enterica. The chambers that exceeded the threshold could be confirmed in the case of $5.0 \times 10^{4} \mathrm{cells} / \mathrm{mL}$ or a higher concentration of S. enterica cells. Moreover, the number of chambers that exceeded the threshold increased depending on the concentration of S. enterica. In addition, the regression line was $y=21.5( \pm 0.91) \ln (x)-40.6( \pm 1.2)$ and $R^{2}=0.99$. The microchambers that exceeded the threshold RFI were considered to have entrapped the immunomagnetic beads binding $S$. enterica cell(s). The number of immunomagnetic beads which bind S. enterica cell(s) depends on the concentration of cells. The number of microchambers which trap immunomagnetic beads to which $S$. enterica cell(s) 
are bound must depend on the concentration of cells. Thus, a linear relationship between the number of microchambers that exceeded the threshold and the concentration of cells indicates that the proposed procedure, including collection of bacteria using the beads, entrapment of the beads in the microchambers, and PCR, reflects the actual concentration of S. enterica cells.

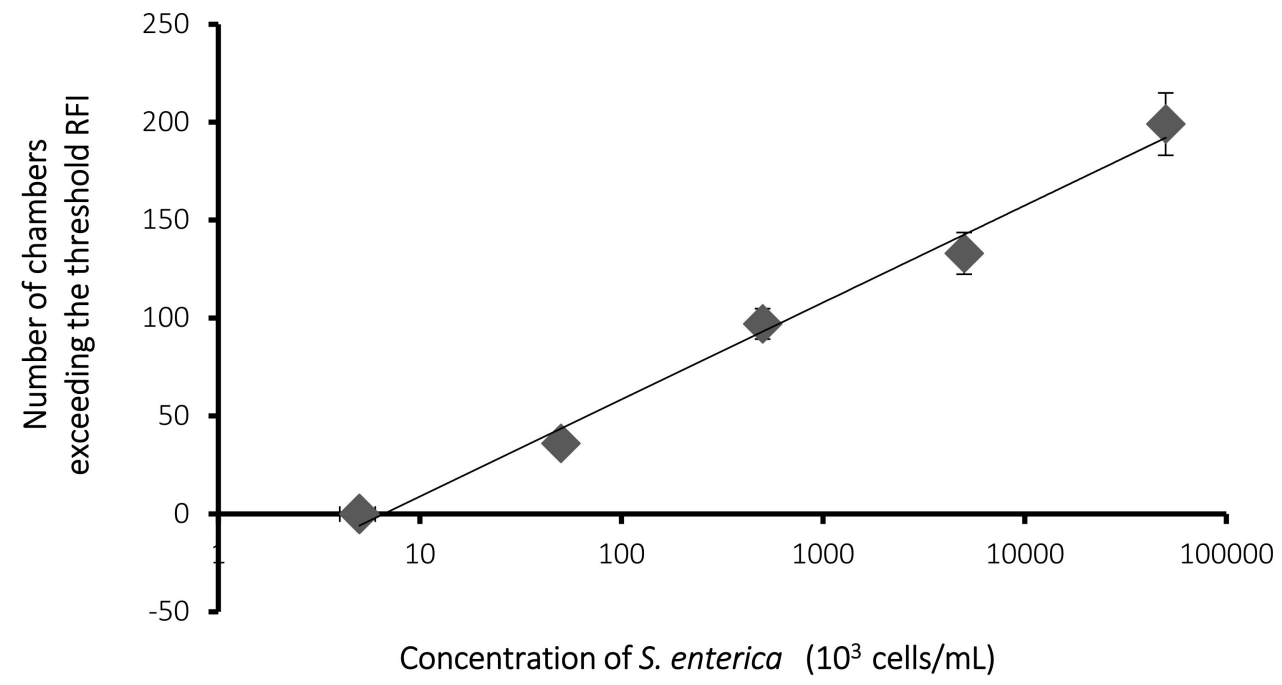

Figure 7. Dependence of the number of microchambers that exceeded the threshold RFI on the concentration of S. enterica. $N=3$.

The collection of S. enterica cells using immunomagnetic beads from egg yolk and PCR was also reported by Vinayaka et al. [24]. In comparison with the same sampling of S. enterica suspended in buffer solution, egg yolk did not affect PCR and almost the same signal and linearity were observed [24]. In this study, the observed detection limit and detectable range were comparable with the observed result without using egg yolk in our previous study [19].

Therefore, it was shown that $S$. enterica collected from egg yolk using beads at 50,000 cells/mL could be detected by PCR on a disc. The detection limit was consistent with a previously reported value [19]. After the collection of S. enterica cells, the detection limit did not change. This indicates that the collection was performed without a significant loss of cells.

Using the proposed method, S. enterica cells in egg yolk were detected by PCR on a microfluidic disc within $6 \mathrm{~h}$. Conventional PCR takes almost $2.5 \mathrm{~h}$, including sample preparation, collection of cells from the egg yolk, mixture with the collected beads with PCR reagent, as well as observation and fluorescent measurement of each microchamber under an epifluorescent microscope. It takes $2 \mathrm{~h}$ to perform PCR on the device. After PCR, fluorescent measurement of each microchamber and calculation of RFI is carried out. Finally, the RFI of each chamber is evaluated to determine which chamber exceeds the RFI threshold. This step requires less than $1 \mathrm{~h}$. In total, within $6 \mathrm{~h}$, a measurement can be completed.

\section{Discussion}

Centrifugation with Percoll ${ }^{\circledR}$ and filtration through polycarbonate membranes were a potential candidate method to separate viable $S$. enterica cells from an egg yolk sample. In this study, the cells could not be separated by these methods successfully, since egg yolk is very thick, and its density is almost the same as bacterial cells [25]. To separate bacterial cells from food samples with similar density, a centrifugal method was investigated [25]. It needs several centrifugal steps with different speeds and times and density gradient procedures. The obtained bacteria could be detected by real-time PCR. This method needs many steps and takes time. In comparison with filtration and/or centrifugal methods, a sampling method based on immunomagnetic beads can separate Salmonella cells from 
egg yolk component(s) easily and sufficiently. This component(s) tends to inhibit PCR. Using this method, viable cells were detected after PCR of a specific gene, inv $A$. The gene was not detected in dead cells. The denaturation of antigen on the surface of cells might prevent them from binding to the immunomagnetic beads.

In the procedure to collect $S$. enterica cells spiked to egg yolk using immunomagnetic beads, the spiked concentration was $5 \times 10^{3}-5 \times 10^{7}$ cells $/ \mathrm{mL}$ to $1 \mathrm{~mL}$ of egg yolk. In order to remove egg yolk, one fifth of the cell suspension $\left(1 \times 10^{3}-1 \times 10^{7}\right.$ cells) was mixed with $10 \mu \mathrm{L}$ of immunomagnetic beads $\left(5 \times 10^{6}\right.$ beads) to collect cells. The number of beads exceeded the number of cells except at the highest concentration $\left(5 \times 10^{7}\right.$ cells/mL). The size of the beads was $2 \mu \mathrm{m}$ in diameter (Supplementary 1 ) and larger than the size of S. enterica cells. Two or more cells can bind to the surface of one bead.

As shown in Figures 6 and 7, a linear relationship between the RFI of PCR and the concentration of cells was observed. This implies that the number of immunobeads was enough to collect the examined concentration of cells. The lowest detectable concentration was $5 \times 10^{4}$ cells $/ \mathrm{mL}$, as shown in Figure 7. As for the detection of S. enterica from chicken meat, $4.6 \times 10^{4} \mathrm{CFU} / \mathrm{g}$ was not detectable without cultivation [11]. After the collection of cells by the beads, the volume was reduced to $100 \mu \mathrm{L}$ $(0.1 \mathrm{~mL})$ from $1 \mathrm{~mL}$, as described in Section 2.4. This indicates that a 10 fold concentration was achieved after collection. Sample preparation using beads resulted in a lower concentration of the sample, which was detected without cultivation. The permissible concentration of S. enterica in food is not yet demonstrated. If a more sensitive assay is needed, the collected sample needs to be cultivated. However, when using immunomagnetic beads, a concentrated sample can be obtained from egg yolk. This method will reduce the cultivation time and shorten the time needed to detect bacteria, including detection on the microfluidic device, relative to direct cultivation methods from egg yolk samples. This difference will be examined in the near future.

The detection of bacteria is necessary for a sensor device because detection of the existence of bacteria is more important than quantification (how many cells exist in the sample) when sensing pathogenic bacteria. The signal (RFI) of the proposed sensor depended on the concentration of the bacteria. This sensor device has the potential for quantification.

The collection of Salmonella cells using immunomagnetic beads and PCR of the hil A gene was also recently reported by Vinayaka et al. [24] as a rapid detection method. However, the method coupled gel electrophoresis and real-time PCR using SYBR ${ }^{\circledR}$ green. Our method does not require gel electrophoresis after PCR and is more rapid than their method.

\section{Conclusions}

S. enterica was collected from egg yolk using a small amount $(10 \mu \mathrm{L})$ of immunomagnetic beads. Fifty thousand cells $/ \mathrm{mL}$ or a higher concentration of $S$. enterica cells in egg yolk was detected by PCR on the microfluidic disc within $6 \mathrm{~h}$, and the PCR reagent used in this method was less than one-tenth of real-time PCR in a micro tube. Since immunomagnetic beads bind viable Salmonella cells, this method provides a rapid and economic formula to detect viable cells without the inhibition of PCR by the egg component. This method may contribute to preventing Salmonella outbreaks.

Supplementary Materials: The following are available online at http://www.mdpi.com/1424-8220/20/4/1060/s1, Supplementary 1: Optical microscopic image of immune magnetic beads.

Author Contributions: I.K. conceptualized the work. I.K. and S.F. wrote the original draft. S.F. designed the microfluidic disc and methodology. M.K. and N.A. conducted PCR analysis in a tube and microfluidic disc device. I.K. was responsible for project administration and funding acquisition. All authors have read and agreed to the published version of the manuscript.

Funding: This research was funded by the Ministry of Education, Culture, Sports, Science and Technology (MEXT), Japan, grant number 17K07825 and the Matching Fund for Private Universities, S1001013, 2010-2015.

Acknowledgments: The authors thank Yuri Aoyama, Soka University for technical support on Real-time PCR.

Conflicts of Interest: The authors declare no conflicts of interest. 


\section{References}

1. Barrow, P.A.; Lovell, M.A. Experimental infection of egg-laying hens with Salmonella enteritidis phage type 4. Avian Pathol. 1991, 20, 335-348. [CrossRef]

2. Shivaprasad, H.L.; Timoney, J.F.; Morales, S.; Luci, B.; Baker, R.C. Pathogenesis of Salmonella enteritidis infection in laying chickens. I. Studies on egg transmission, clinical signs, fecal shedding, and serological responses. Avian Dis. 1990, 343, 548-557. [CrossRef]

3. Ebel, E.D.; David, M.J.; Mason, J. Occurrence of Salmonella enteritidis in the U.S. commercial egg industry: Report on a national spent hen survey. Avian Dis. 1992, 36, 646-654. [CrossRef] [PubMed]

4. Hogue, A.T.; Ebel, E.D.; Thomas, L.A.; Schlosser, W.; Bufano, N.; Ferris, K.E. Surveys of Salmonella enteritidis in unpasteurized liquid egg and spent hens at slaughter. J. Food Prot. 1997, 60, 1194-1200. [CrossRef] [PubMed]

5. Ohtsuka, K.; Yanagawa, K.; Takatori, K.; Hara-Kudo, Y. Detection of Salmonella enterica in naturally contaminated liquid eggs by loop-mediated isothermal amplification, and characterization of Salmonella isolates. Appl. Environ. Microbiol. 2005, 71, 6730-6735. [CrossRef] [PubMed]

6. Kogut, M.H.; Arsenault, R.J. Immunometabolic phenotype alterations associated with the induction of disease tolerance and persistent asymptomatic infection of Salmonella in the chicken intestine. Front. Immunol. 2017, 8, 1-7. [CrossRef]

7. Barrow, P.A. The paratyphoid Salmonellae. Rev. Sci. Tech. 2000, 19, 351-375. [CrossRef]

8. Barrow, P.A.; Bumstead, N.; Marston, K.; Lovell, M.A.; Wigley, P. Fecal shedding and intestinal colonization of Salmonella enterica in in-bred chickens: The effect of host-genetic background. Epidemiol. Infect. 2004, 132, 117-126. [CrossRef]

9. Monack, D.M. Helicobacter and Salmonella persistent infection strategies. Cold Spring Harb. Perspect. Med. 2013, 3, 1-18. [CrossRef]

10. Environmental Health Bureau; Ministry of Health and Welfare. Biology. In Standard Methods of Analysis in Food Safety Regulation; Japan Food Hygiene Association: Tokyo, Japan, 1990.

11. Furutani, S.; Kajiya, M.; Aramaki, N.; Kubo, I. Rapid detection of Salmonella enterica in food using a compact disc-shaped device. Micromachines 2016, 7, 10. [CrossRef]

12. Tan, T.T.; Tan, Z.Y.; Tan, W.L.; Lee, P.F. Gel electrophoresis: DNA science without the DNA! Biochem. Mol. Biol. Educ. 2007, 35, 342-349. [CrossRef] [PubMed]

13. Verdoy, D.J.; Marimon, M.; Olabarria, G. A novel real time micro PCR based point-of-care device for Salmonella detection in human clinical samples. Biosens. Bioelect. 2012, 32, 259-265. [CrossRef] [PubMed]

14. Heymans, R.; Vila, A.; Van, H.C.A.M.; Jansen, C.C.C.; Castelijn, G.A.A.; Van, D.V.M.; Biesta-Peters, E.G. Rapid detection and differentiation of Salmonella species, Salmonella typhimurium and Salmonella enteritidis by multiplex quantitative PCR. PLoS ONE 2018, 13. [CrossRef] [PubMed]

15. Furutani, S.; Nagai, H.; Kubo, I. Single cell isolation on a centrifugal flow disk with integrated tandem microchambers. Sens. Lett. 2008, 6, 961-965. [CrossRef]

16. Furutani, S.; Nagai, H.; Takamura, Y.; Aoyama, Y.; Kubo, I. Detection of expressed gene in isolated single cells in microchambers by a novel hot cell-direct RT-PCR method. Analyst 2012, 137, 2951-2959. [CrossRef]

17. Kubo, I.; Itoh, Y.H.; Furutani, S. Hot cell-direct PCR aimed at specific cell detection, In Polymerase Chain Reaction for Biomedical Applications; Samadikuchaksaraei, A., Ed.; INTECH: Rijeka, Croatia, 2016; pp. 39-56.

18. Furutani, S.; Shozen, N.; Nagai, H.; Aoyama, Y.; Kubo, I. Development of a detection system for expressed genes in isolated single cells. Sens. Mater. 2014, 26, 623-625.

19. Furutani, S.; Nagai, H.; Takamura, Y.; Kubo, I. Compact disk (CD)-shaped device for single cell isolation and PCR of a specific gene in the isolated cell. Anal. Bioanal. 2010, 398, 2997-3004. [CrossRef]

20. Schwan, W.R.; Huang, X.Z.; Hu, L.; Kopecko, D.J. Differential bacterial survival, replication, and apoptosis-inducing ability of Salmonella serovars within human and murine macrophages. Infect. Immun. 2000, 68, 1005-1013. [CrossRef]

21. Percoll Density Gradient Mmedia. Available online: https://www.gelifesciences.com/ja/jp/shop/cell-therapy/ media/percoll-density-gradient-media-p-05823 (accessed on 1 November 2019).

22. Dynabeads Anti-Salmonella. Available online: https://assets.thermofisher.com/TFS-Assets/LSG/manuals/ dynabeads_antisalmonella_man.pdf (accessed on 1 November 2019). 
23. Lynch, M.J.B.; Leon-Velarde, C.G.; McEwen, S.; Odumeru, J.A. Evaluation of an automated immunomagnetic separation method for the rapid detection of Salmonella species in poultry environmental samples. J. Microbiol. Methods. 2004, 58, 285-288. [CrossRef]

24. Vinayaka, A.C.; Ngo, T.A.; Kant, K.; Engelsmann, P.; Dave, V.P.; Shahbazi, M.A.; Wolff, A.; Bang, D.D. Rapid detection of Salmonella enterica in food samples by a novel approach with combination of sample concentration and direct PCR. Biosens. Bioelectron. 2019, 129, 224-230. [CrossRef]

25. Fukushima, H.; Katsube, K.; Hata, Y.R.; Fujiwara, S. Rapid separation and concentration of food-borne pathogens in food samples prior to quantification by viable-cell counting and real-time PCR. Appl. Environ. Microbiol. 2007, 73, 92-100. [CrossRef] [PubMed]

(C) 2020 by the authors. Licensee MDPI, Basel, Switzerland. This article is an open access article distributed under the terms and conditions of the Creative Commons Attribution (CC BY) license (http://creativecommons.org/licenses/by/4.0/). 